\title{
II PREMIO JOSÉ MANUEL ESTEVE
}

La Facultad de Ciencias de la Educación de la Universidad de Málaga, con el fin de reconocer y recordar la labor docente e investigadora en el campo de la Pedagogía del que fue catedrático de Teoría de la Educación de esta Universidad y Doctor Honoris Causa por la Universidad de Oviedo, profesor José Manuel Esteve Zarazaga, ha acordado convocar el II PREMIO JOSÉ MANUEL ESTEVE.

Teniendo en cuenta la importante contribución del profesor Esteve a la investigación de los cambios sociales que se han producido en las últimas décadas y que tanto han incidido en el mundo de la educación, de los docentes y de la Pedagogía, el objetivo de este premio es el fomento y difusión de trabajos pedagógicos que contribuyan a dar a conocer, difundir y profundizar en la reflexión y análisis de la educación, de su ejercicio profesional y de sus ámbitos de actuación.

El Premio se convoca con carácter anual y ámbito internacional, de acuerdo con las siguientes bases:

1) Podrán concurrir al premio todos aquellos artículos que hayan sido publicados en castellano, en revistas científicas de educación en el transcurso del 2011.

2) La extensión máxima será de 15.000 palabras.

3) Los/las concurrentes presentarán un solo artículo para su estimación.

4) Se abstendrán de concurrir al premio durante un periodo de tres años las personas premiadas en ediciones anteriores.

5) Los artículos se remitirán por quintuplicado, antes del 31 de julio de 2012, en sobre cerrado dirigido a:

"Premio José Manuel Esteve"

Facultad de Ciencias de la Educación (Decanato)

Campus de Teatinos

29071 Málaga

6) El premio José Manuel Esteve está dotado con $3.000 €$. No se efectuará acto de entrega y podrá declararse desierto. En caso de autoría compartida, la entrega se hará a la primera persona firmante.

7) El jurado estará constituido por el Decano/a de la Facultad de Ciencias de la Educación, un miembro del Departamento de Teoría e Historia de la Educación, otro del de Didáctica y Organización Escolar, otro elegido por la Junta de Facultad y el Dr. D. Joaquín García Carrasco, ganador de la primera edición.

8) La composición del jurado se dará a conocer coincidiendo con el fallo del concurso que será inapelable y se comunicará en octubre de 2012.

9) La Facultad de Ciencias de la Educación podrá publicar el artículo premiado y no devolverá originales ni mantendrá correspondencia con los autores/as.

10) La presentación a este premio supone la aceptación de estas bases. 


\section{PREMIO JOSÉ MANUEL ESTEVE}

\section{Acta de constitución y fallo del jurado}

El 31 de octubre de 2011 se reúne en la Facultad de Ciencias de la Educación de la Universidad de Málaga el Jurado de la primera edición del Premio José Manuel ESTEVE compuesto por:

Presidente:

- Don José Francisco Murillo Mas, Decano de la Facultad de Ciencias de la Educación de la Universidad de Málaga.

Vocales

- Doña Dolores Alcántara Sacristán, representante del Departamento de Didáctica y Organización Escolar de esta Facultad,

- Don Cristóbal González Álvarez, representante elegido por la Junta de Centro.

- Don José Vicente Peña Calvo, padrino del Dr. Esteve en el acto de investidura cono Doctor Honoris Causa por ta Universidad de Oviedo,

Secretaria:

- Dỗa Carmen Saachidrián Blanco, representante del Departamento de Teoria e Historia de la Educacion

El jurado ha valorado los 14 artículos presentados, agradeciendo a todos los autores su participación en este Premio, acordando, por unanimidad, conceder el I PREMIO JOSÉ MANUEL ESTEVE a Don Joaquín García Carrasco, por su artículo titulado "Madurez cultural y educación permanente en la sociedad de la información", publicado en la revista Bordon, 2010, 63(3).

El jurado ha acordado la concesión đe prenio al articulo citado por la profundidad del análisis, la actualidad de la temática, la relevancia de las fuentes y la calidad expositiva del texto a lo que hay que añadir, además, su hondura pedagógica.

Lo que firmo como secretaria en Málaga, a 31 de octubre de 2011.

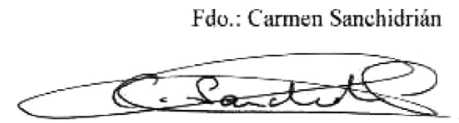

miércoles, 09 de noviembre de 2011 (2).max 